\title{
Effect of formoterol on clinical parameters and lung functions in patients with bronchial asthma: a randomised controlled trial
}

\author{
Akgül Akpınarlı, Ayfer Tuncer, Yıldız Saraçlar, Bülent E Şekerel, Ömer Kalaycı
}

\begin{abstract}
Aims-To determine the role of formoterol in the treatment of children with bronchial asthma who are symptomatic despite regular use of inhaled corticosteroids.

Methods-A randomised, double blind, parallel group, placebo controlled study to investigate the effects of inhaled formoterol (12 $\mu \mathrm{g}$ twice a day) in 32 children with moderate to severe bronchial asthma. The study consisted of two week run in periods and six week treatment periods, during both of which the patients continued their regular anti-inflammatory drugs. The efficacy parameters were symptom scores, bronchodilator use, daily peak expiratory flow rates (PEFR), methacholine hyper-reactivity, forced expiratory volume in one second $\left(\mathrm{FEV}_{1}\right)$, lung volumes, and airway conductance.

Results-Formoterol treatment for six weeks decreased symptom scores, PEFR variability, and the number of rescue salbutamol doses, and increased morning and evening PEFR significantly. No adverse reactions were seen.

Conclusion-These findings suggest that inhaled formoterol is effective in controlling chronic asthma symptoms in children who are symptomatic despite regular use of inhaled corticosteroids.

(Arch Dis Child 1999;81:45-48)
\end{abstract}

Keywords: bronchial asthma; formoterol; asthma; randomised controlled trial

Inhaled $\beta_{2}$ agonists are the mainstay of symptomatic asthma treatment. The introduction of long acting $\beta_{2}$ agonists has brought a new dimension to symptomatic treatment. The long lasting bronchodilating effect of this new class of medications is especially desirable for children, who have longer night rests and more frequent periods of extensive physical activity than most adults. Another advantage offered by long acting $\beta_{2}$ agonists is their twice a day application, which results in increased patient compliance. ${ }^{12}$ Formoterol is a new long and rapid acting, selective $\beta_{2}$ agonist with a bronchodilator effect lasting 12 hours. ${ }^{3}$ In adult patients with asthma, it is currently recommended as an alternative to increasing moderate doses of inhaled corticosteroids or as an adjunct to high doses of inhaled corticosteroids. $^{45}$ A survey of the medical literature failed to disclose any studies that have investigated the role of formoterol for the treatment of children with asthma who are symptomatic despite inhaled corticosteroids.

In a randomised, double blind, placebo controlled, parallel group study we investigated the effect of formoterol treatment in children with bronchial asthma of moderate severity who were symptomatic despite regular use of inhaled corticosteroids.

\section{Methods}

PATIENTS

Thirty two children with asthma (15 boys and 17 girls), ranging in age from 6 to 14 years (mean, 10.25; SEM, 2.31), recruited from the outpatient clinic of the pediatric allergy and asthma division of Hacettepe University School of Medicine were enrolled in the study. All patients met the American Thoracic Society criteria for bronchial asthma ${ }^{6}$ and demonstrated at least a $15 \%$ change in forced expiratory volume in one second $\left(\mathrm{FEV}_{1}\right)$ within the previous year. Twenty one patients were atopic as determined by skin prick testing. Patients with pollen sensitivity were studied outside the pollen season. All patients had moderate persistent asthma, ${ }^{4}$ and were symptomatic despite regular inhaled corticosteroids (400-800 $\mu \mathrm{g} /$ day). Only those patients who had had no asthma exacerbation or respiratory infection within the last month were included in our study. Asthma exacerbation was defined as a sudden increase in asthma symptoms accompanied by signs of dyspnoea that necessitated the addition of systemic corticosteroids or increases in bronchodilator use.

All patients and their parents gave their informed consent and the study was approved by the local ethics committee.

DESIGN

The study protocol covered two periods: a two week run in and a six week treatment period. During the run in period, in addition to their regular anti-inflammatory treatment, patients were allowed salbutamol on demand. Only those patients who needed salbutamol more than once a week went on to the treatment period.

Patients were randomised into two groups to receive either $12 \mu \mathrm{g}$ of formoterol or placebo twice daily for six weeks. Formoterol and placebo were supplied in identical canisters and administered with a large volume spacer (Volumatic; Glaxo Welcome, Istanbul, Turkey). Inhaled $\beta_{2}$ agonists were allowed on demand throughout the treatment period. 
Table 1 Characteristics of the two treatment groups

\begin{tabular}{lll}
\hline & Formoterol & Placebo \\
\hline Number & 16 & 16 \\
Boys/girls & $7 / 9$ & $8 / 8$ \\
Mean follow up (years) (range) & $3.09(1-7.5)$ & $3.34(1-7)$ \\
Mean steroid use (years) (range) & $1.12(0.5-2.5)$ & $1.58(0.5-3.3)$ \\
Atopy & 11 & 10 \\
\hline
\end{tabular}

Patients were seen at the clinic on three occasions: at the end of the run in period (baseline visit), at the third, and at the sixth week of the treatment period (first and second visits, respectively).

On each visit, lung functions including $\mathrm{FEV}_{1}$, specific conductance (sGaw), total lung capacity (TLC), and residual volume (RV) were measured. The concentration of methacholine causing a $20 \%$ decrease in $\mathrm{FEV}_{1}$ (PC20) was determined at baseline and second visit only. All measurements were performed at the same time of day (08:00-09:00), starting with sGaw. Inhaled medications were withheld for at least 12 hours before each visit. Throughout our study, the children or their parents were instructed to keep a diary of asthma symptoms. Symptoms of night and daytime cough, wheezing, and shortness of breath were rated on a scale from 0 to 3, giving a maximum possible daily score of 9 .

Patients also recorded the best of three measurements of morning and evening peak expiratory flow rates (PEFR) and the number of supplemental $\beta_{2}$ agonist inhalations (salbutamol $100 \mu \mathrm{g} \times 2$ ). Compliance with the dosing regimen was assessed by weighing the canisters before and after treatment periods. On each visit blood pressure was measured, and an electrocardiogram (ECG) and blood chemistry measurements (glucose and potassium) were performed on each patient.

PULMONARY FUNCTION TESTS

Specific conductance, TLC, and RV were measured in a whole body, pressure/volume (flow) plethysmograph (Autobox DL 6200; Sensor Medics Co, Anaheim, California, USA) and results were given as per cent of predicted. Patients were instructed to pant slowly $(<1 \mathrm{~Hz})$ to minimise the overestimation of lung volume, which has been reported to occur in the presence of airway obstruction. ${ }^{78}$ Each measurement was repeated until three reproducible results within $10 \%$ of each other were obtained with consistent effort; the mean of these three measurements was recorded.

Forced expiratory manoeuvers were recorded on a dry rolling seal spirometer (2130 Spirometer; Sensor Medics Co) and the maximal value of three $\mathrm{FEV}_{1}$ measurements was selected.

Methacholine challenge was carried out according to a previously described protocol, ${ }^{9}$ which is a modification of Cockroft's. ${ }^{10}$ Briefly, after saline inhalation, doubling concentrations of methacholine solution were inhaled during a two minute tidal breathing period every five minutes, starting with $0.03 \mathrm{mg} / \mathrm{ml}$, until a fall in $\mathrm{FEV}_{1}$ of at least $20 \%$ was obtained. PC20 was calculated by linear interpolation on the log dose response curve. The aerosols were generated by a nebuliser (Model 646; DeVilbiss Co, Somerset, Pennsylvania, USA) attached to an air compressor (Pulmo-Aid; DeVilbiss Co) giving an output of $0.23-0.25 \mathrm{ml} /$ minute. The same nebuliser was used for each challenge. Duplicate spirometry was performed at 0.5 and 1.5 minutes after each inhalation. The patients wearing nose clips were challenged while their arterial $\mathrm{O}_{2}$ saturation was continuously monitored for safety reasons.

\section{STATISTICAL ANALYSIS}

The PC20 values were log transformed for analysis and expressed as geometric mean values. The morning and evening PEFR values were calculated as daily means for each two week period. The asthma score and the number of supplemental $\beta_{2}$ agonist uses were given as weekly means. Analysis within each group was performed by the Friedmann two way ANOva test, and the Wilcoxon test was used whenever the analysis of variance gave significant results. The formoterol and placebo groups were compared using the MannWhitney $\mathrm{U}$ test. A p value $<0.05$, using the two tailed test, was considered to be significant.

Table 2 Clinical parameters and lung functions of the two groups

\begin{tabular}{|c|c|c|c|c|c|c|}
\hline & \multicolumn{3}{|l|}{ Formoterol } & \multicolumn{3}{|l|}{ Placebo } \\
\hline & Baseline (week 0) & $\begin{array}{l}\text { Change at first visit } \\
\text { (week 3) from baseline }\end{array}$ & $\begin{array}{l}\text { Change at second visit } \\
\text { (week 6) from } \\
\text { baseline }\end{array}$ & Baseline (week 0) & $\begin{array}{l}\text { Change at first } \\
\text { visit (week 3) from } \\
\text { baseline }\end{array}$ & $\begin{array}{l}\text { Change at second visit } \\
\text { (week 6) from } \\
\text { baseline }\end{array}$ \\
\hline $\mathrm{FEV}_{1}(\%$ predicted $)$ & 79 (60 to 116$)$ & 9.5 ( -6 to 30$)$ & $3.0(-23$ to 29$)$ & $80(63$ to 107$)$ & $1.0(-12$ to 19$)$ & $1.0(-12$ to 19$)$ \\
\hline sGaw (\% predicted) & 77.5 (53 to 150$)$ & $3.5(-48$ to 13$)$ & $0(-42$ to 107$)$ & 62.5 (29 to 96$)$ & $2.0(-37$ to 107$)$ & $10(-23$ to 90$)$ \\
\hline TLC (\% predicted) & $103.5(90$ to 187$)$ & $4.5(-14$ to 42$)$ & $4.5(-17$ to 53$)$ & 109 (89 to 125$)$ & $2.5(-34$ to 88$)$ & $5.0(-11$ to 42$)$ \\
\hline RV (\% predicted) & $159(85$ to 372$)$ & $1.5(-91$ to 54$)$ & 5.5 ( -82 to 259$)$ & 133 (73 to 304$)$ & -0.5 ( -79 to 385$)$ & $7.5(-5.8$ to 192$)$ \\
\hline FVC (\% predicted) & 91 (69 to 137$)$ & $2.5(-33$ to 35$)$ & $1.5(-31$ to 40$)$ & $94(76$ to 121$)$ & $4.5(-16$ to 84$)$ & $3.0(-9$ to 17$)$ \\
\hline FRC (\% predicted) & 132.5 (94 to 234$)$ & $-4(-42$ to 62$)$ & $4.5(-48$ to 150$)$ & 132.5 (98 to 200$)$ & $4.5(-32$ to 186$)$ & $6.5(-41$ to 112$)$ \\
\hline PC20 $(\mathrm{mg} / \mathrm{ml})$ & 0.295 (0.04 to 1.87$)$ & - & $0.050(0.57$ to 0.74$)$ & $0.3(0.08$ to 2.24$)$ & - & $0.02(-0.5$ to 0.46$)$ \\
\hline mPEFR (1/min) & 239.5 (129 to 295$)$ & $11.5^{\star}(-2$ to 206$)$ & $19^{\star}(2$ to 181$)$ & $212.5(144$ to 390$)$ & $1.0(-24$ to 50$)$ & $0(-35$ to 43$)$ \\
\hline ePEFR (1/min) & 243.5 (139 to 303$)$ & $10.5^{\star}(-10$ to 166$)$ & $19^{\star}(-9$ to 148$)$ & 219 (145 to 390$)$ & $-1.0(-46$ to 50$)$ & $0(-47$ to 20$)$ \\
\hline vPEFR (\%) & 2.75 (0 to 12$)$ & $-1.125^{\star}(-9$ to 3.33$)$ & $-1.3^{\star}(-12$ to 2.4$)$ & $2.0(0$ to 17$)$ & $-0.2(-16$ to 2.4$)$ & $0(-24$ to 1.8$)$ \\
\hline$\beta_{2}$ agonist uset (per week) & $3.0(2$ to 6$)$ & $-2^{\star}(-4$ to -1$)$ & $-3^{\star}(-6$ to -2$)$ & $3.0(2$ to 10$)$ & $-1.0^{\star}(-2$ to 1$)$ & $0(-2$ to 2$)$ \\
\hline Asthma symptom score & $3.0(2$ to 7$)$ & $-3^{\star}(-5$ to -2$)$ & $-3^{\star}(-7$ to -2$)$ & 3.5 (2 to 12$)$ & $-1.0^{\star}(-4$ to 0$)$ & $0(-1$ to 1$)$ \\
\hline
\end{tabular}

${ }^{\star} \mathrm{p}<0.05$ compared with the corresponding baseline value (Wilcoxon test).

$\dagger$ Each use consisted of two puffs of salbutamol (100 $\mu \mathrm{g} / \mathrm{puff})$.

$\ddagger$ Night time cough, daytime cough, wheezing or shortness of breath rated on a scale from 0 to 3 (maximum, 9).

ePEFR, evening peak expiratory flow rate; $\mathrm{FEV}_{1}$, forced expiratory volume in one second; FRC, functional residual capacity, FVC; forced vital capacity; mPEFR, morning peak expiratory flow rate; PC20, $20 \%$ decrease in $\mathrm{FEV}_{1}$; RV, residual volume; sGAW, specific conductance; TLC, total lung capacity; vPEFR, variability of peak expiratory flow rate. 

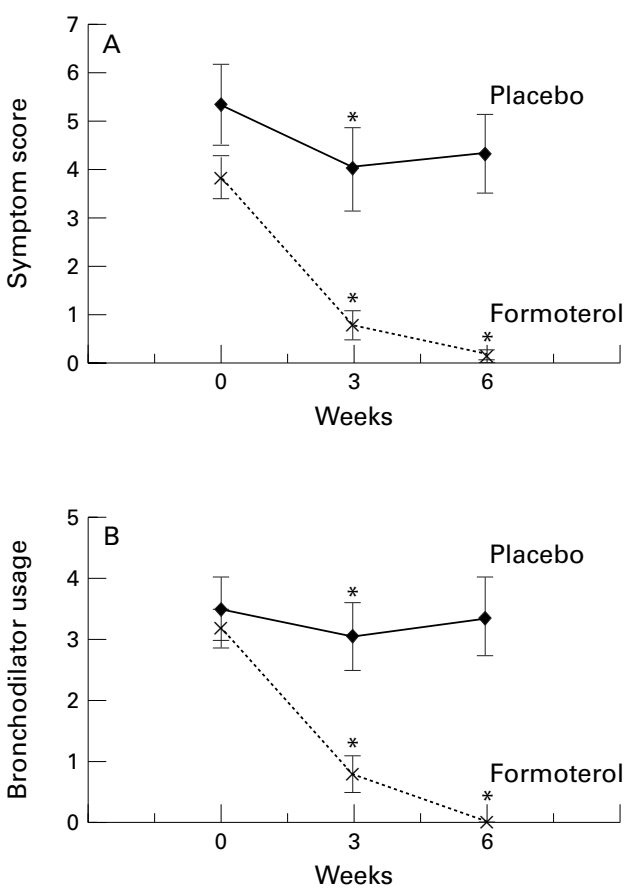

Figure 1 (A) The effects of formoterol and placebo on symptom scores. (B) The effects of formoterol and placebo on bronchodilator use.

\section{Results}

Of the 32 children, 16 were treated with placebo and 16 with formoterol during the treatment period. At the time of randomisation, the two groups had similar characteristics (table 1). There were no asthma exacerbations that required systemic corticosteroids during the study periods. Neither an asthmatic attack nor an infection was noted for at least two weeks preceding each clinic visit.

Compliance with the use of study drugs was greater than $85 \%$ for each group. There were no differences between the two groups in this regard. Tolerance to formoterol was good in all patients. There was no evidence of effects as measured by ECG changes, blood pressure, and blood chemistry, and no patient complained of headache.

Table 2 summarises the results. Placebo treatment failed to cause any significant changes in any variables during the six weeks of

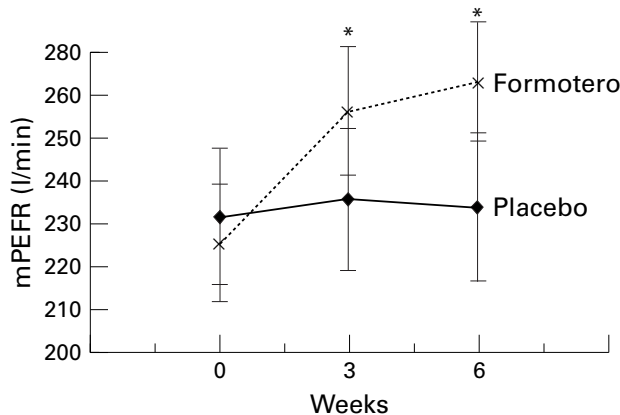

Figure 2 Changes in mean morning peak expiratory flow rates (mPEFR). Forced vital capacity, forced expiratory volume in one second (FEV,), specific conductance (sGaw), total lung capacity (TLC), functional residual capacity, residual volume (RV), and $20 \%$ decrease in FEV (PC20) values were not significantly different before and after treatment in either group. The comparison between the two groups did not show any significance at any time point. treatment, except lower symptom scores and $\beta_{2}$ agonist use at first visit compared with baseline ( $\mathrm{p}=0.04$ and 0.05 , respectively). However, the figures obtained for these same variables were not significantly different from the baseline at the second visit ( $p>0.05$ for both) (fig $1 \mathrm{~A}$ and B). On the other hand, formoterol treatment caused significant decreases in symptom scores and $\beta_{2}$ agonist use at both the first and second visits (fig $1 \mathrm{~A}$ and $\mathrm{B}$; table 2 ). Both morning and evening PEFR values (at first and second visits) were significantly higher compared with baseline (fig 2; table 2). As expected, PEFR variability followed a similar trend and was significantly lower at first and second visits compared with baseline (table 2).

\section{Discussion}

Formoterol, a new long acting bronchodilator, is suggested as an alternative to increasing the amount of inhaled corticosteroids in asthma patients who are symptomatic despite the regular use of these drugs. This recommendation is based on the results of studies conducted in the adult population. ${ }^{11}$ Our study suggested that formoterol is effective in improving clinical symptoms as well as some pulmonary function measures in children, and was not associated with adverse effects, at least during the six week treatment period.

Previous studies in children have shown that formoterol may be useful in exercise induced asthma, ${ }^{12}{ }^{13}$ and that it may increase PEFR ${ }^{14}$ and decrease bronchial hyperreactivity. ${ }^{15}$ The improvement seen in morning and evening PEFRs clearly shows the sustained bronchodilating action of formoterol. We think that the accompanying decrease in PEFR variability should also be attributed to this bronchodilating effect rather than to a possible antiinflammatory effect. The fact that formoterol treatment did not effect PC20 values is also indicative of the lack of an anti-inflammatory effect. This might be a result of the small number of children in our study, but this explanation is unlikely because of the complete absence of an effect in any patient. These results are different from those reported by Becker and Simons, ${ }^{15}$ where after $12 \mu \mathrm{g}$ formoterol, airway responsiveness to methacoline was significantly blunted for as long as 12 hours when compared with the placebo. The reasons for the discrepancy between the two studies are unclear. However, all the patients in our study were on inhaled corticosteroids, compounds known to decrease bronchial hyperreactivity significantly, which might explain why formoterol had no additional beneficial effect on hyperreactivity.

Bronchodilation provided by formoterol was sustained throughout the study as reflected by higher PEFR values and lower symptom scores and $\beta_{2}$ agonist use at the end of six weeks. These findings suggest that six weeks of formoterol treatment did not cause the development of tolerance.

In our patients, asthma was associated with lung hyperinflation as indicated by increased TLC and RV values. Previously, we have shown that inhaled corticosteroids can decrease TLC 
in asthmatic children. ${ }^{9}$ However, unlike corticosteroids, formoterol does not seem to influence the lung hyperinflation caused by bronchial asthma.

We think that the use of a long acting $\beta_{2}$ agonist should be considered in children in whom inhaled corticosteroids may have the potential to retard linear growth, especially at higher doses. ${ }^{16-19}$ Our results suggest that adding formoterol to inhaled corticosteroids is an effective treatment option in children who are symptomatic despite regular use of inhaled corticosteroids.

1 Harold SN. $\beta$-Adrenergic bronchodilators. $N$ Engl $\mathcal{F ~} \mathrm{Med}$ 1995;33:499-505.

2 Barnes PJ. New drugs for asthma. Clin Exp Allergy 1996;26: 735-45.

3 Anderson GP. Formoterol: pharmacology, molecular basis of agonism, and mechanism of long duration of a highly potent and selective $\beta_{2}$-adrenoceptor agonist bronchodilator. Life Sci 1993;52:2145-60.

4 Global Initiative for Asthma. Global strategy for asthma management and prevention NHLBI/WHO workshop report. National heart, lung, and blood institute publication. Number 95-3659, January 1995.

5 Arvidsson P, Larsson S, Löfdahl CG, Melander B, Svedmyr $\mathrm{N}$, Wahlander L. Inhaled formoterol during one year in asthma: a comparison with salbutamol. Eur Respir $\mathscr{f} 1991$; asthma: a com

6 American Thoracic Society. Standards for the diagnosis and care of patients with chronic obstructive pulmonary disease and asthma. Am Rev Respir Dis 1987;135:225-53.
7 Shore SA, Huk O, Manniw S, Martin JG. Effect of panting frequency on the plethysmographic determination of frequency on the plethysmographic determination of thoracic gas volume in chronic obstruct

ease. Am Rev Respir Dis 1983;128:54-9.
8 Brown R, Ingram RH, McFadden ER. Problems in the plethysmograhic assessment of changes in total lung capacity in asthma. Am Rev Respir Dis 1978;118:685-92.

9 Şekerel BE, Tuncer A, Saraçlar Y, Adalıoglu G. Inhaled budesonide reduces lung hyperinflation in children with asthma. Acta Paediatr 1997;86:932-6.

10 Cockroft DW, Killian DN, Mellon JJA, Hargreave FE. Bronchial reactivity to inhaled histamine: a method and clinical survey. Clin Allergy 1977;7:235-43.

11 Pauwels RA, Löfdahl CG, Postma DS, et al. Effect of inhaled formoterol and budesonide on exacerbations of asthma. N Engl f Med 1997;337:1405-11.

12 Boner AL, Spezia E, Piovesan P, Chiocca E, Maiocchi G. Inhaled formoterol in prevention of exercise-induced bronchoconstriction in asthmatic children. Am f Respir Crit Care Med 1994;149:935-9.

13 Henriksen MJ, Agetoft L, Pedersen S. Protective effect and duration of action of inhaled formoterol and salbutamol on exercise-induced asthma in children. $\mathcal{F}$ Allergy Clin Immunol 1992;89:1176-82.

4 von Berg A, Berdel D. Efficacy of formoterol metered aerosol in children. Lung 1990;168(suppl):90-8.

15 Becker BA, Simons FE. Formoterol, a new long-acting selective $\beta_{2}$-agonist, decreases airway responsiveness in children with asthma. Lung 1990;168(suppl):99-102

16 Simons FER. A comparison of beclomethasone salmeterol and placebo in children with asthma. $N$ Engl $7 \mathrm{Med}$ 1997;337:1659-65.

17 Wales JKH, Barnes ND, Swift PGF. Growth retardation in children on steroids for asthma. Lancet 1991;338:1535-41.

18 Crowley S, Hindmarsh PC, Matthews DR, Brook CGD. Growth and growth hormone axis in prepubertal children with asthma. F Pediatr 1995;126:297-303.

19 Saha MT, Laippala P, Lenko HL. Growth of asthmatic children is slower during than before treatment with inhaled glucocorticoids. Acta Paediatr 1997;86:138-42. 